\begin{tabular}{|c|l|}
\hline Title & A Iternative Objectives in an Oligopoly Model : An Aggregative Game A pproach \\
\hline Author(s) & Itaya, Jun-ichi; Cornes, Richard \\
\hline Citation & Discussion Paper, Series A, 307, 1-31 \\
\hline Issue Date & 2016-11-06 \\
\hline Doc URL & http://hdl.handle.net/2115/63516 \\
\hline Type & bulletin (article) \\
\hline File Information & DPA 307.pdf \\
\hline
\end{tabular}

Instructions for use 
Discussion Paper, Series A, No.2016-307

Alternative Objectives in an Oligopoly Model: An

Aggregative Game Approach

Richard Cornes, Jun-ichi Itaya

November 2016

Graduate School of Economics \&

Business Administration

Hokkaido University

Kita 9 Nishi 7, Kita-Ku, Sapporo 060-0809, JAPAN 


\title{
Alternative Objectives in an Oligopoly Model: An Aggregative Game Approach
}

\author{
Richard Cornes * Jun-ichi Itaya $^{\dagger}$
}

November 6, 2016

\begin{abstract}
A rapidly growing literature analyzes models in which firms maximize objectives other than profit and enjoy market power. Examples include the labor-managed firm, mixed oligopoly, and delegation models. These models typically retain the aggregative structure of the conventional Cournot model of imperfect competition. We exploit this fact and apply the framework recently developed by Cornes and Hartley $(2005,2011)$ to analyze the properties of the equilibrium in such games. We show that existing treatments often make more restrictive assumptions than necessary to generate their results. Specifically, we identify conditions sufficient to ensure the existence of a unique equilibrium, and we explore the comparative static properties of these conditions.
\end{abstract}

Keywords: Aggregative Game, Oligopoly, Hahn's Condition, Non-profit Maximization, Share Function

JEL classifications: C72, D43, L21

${ }^{*}$ F. H. Gruen Professor of Economics, Research School of Economics, Australian National University. E-mail address: rccornes@aol.com.

†Corresponding author: Graduate School of Economics and Business Administration, Hokkaido University, Sapporo, 060-0809, JAPAN. Tel: +81-11-706-2858; fax: +81-11-706-4947. E-mail address: itaya@econ.hokudai.ac.jp. 


\section{Introduction}

Traditional economic theories of firms assume that the sole aim of firms is profit maximization. However, this assumption has been criticized by management researchers and economists who have studied the organization as well as modern corporations. They argue that the complexity of the managerial decision process and the separation of ownership and control, which is common to most large-scale corporations, would lead managers to maximize an alternative objective other than profits. If firms are likely to move away from profit-maximizing behavior, what is the alternative? In the 1980s, Vickers (1985), Fershtman (1985), Fershtman and Judd (1987), and Sklivas (1987) (hereafter, VFJS for short) examined a two-stage delegation game in which, in the first stage, the owner maximizes profit by properly choosing the weights on profit and sale revenue in the manager's incentive contract, and, in the second stage, the manager maximizes the objective function given the weights chosen in the first stage. These papers led to fruitful studies in which researchers adopted the basic structure of this delegation game. Among these studies, Fumas (1992) and Miller and Pazgal (2002) consider a two-stage delegation game in which the manager's incentive contract is based on a weighted sum of the firm's own profit and its rivals' profits (or their average profits). More recently, Jansen et al. (2007) and Ritz (2008) further consider the delegation game whose managerial incentive scheme is a weighted average of profits and market share. They show that managers can achieve more profits for owners with decisions based partly on non-profit considerations like sales, production volumes, market share, and so on than with decisions driven solely by profit. This literature usually assumes not only that the manager's incentive contract is composed of a linear combination of profit and a non-profit indicator but also that the market features oligopolistic competition with linear demand and linear/quadratic production cost functions.

Since most of the papers in the literature have assumed linear inverse demand and linear or quadratic production cost functions for mathematical tractability, each oligopoly firm has a linear reaction function. This means that issues such as the existence, uniqueness, and stability of a Cournot-Nash equilibrium in oligopolistic competition is of secondary importance. Moreover, the assumption of symmetric firms has been employed quite often in the setting 
of $n$ firms. Such simplification severely limits the validity and applicability of the results of these models. In order to assess the robustness of the comparative statics, we need to investigate an oligopoly model under more general (or non-linear) demand and cost functions. However, if we allow for more general demand and cost functions, the resulting oligopoly model may exhibit multiple equilibria and/or lead to inconclusive comparative statics, which in turn significantly reduces the predictability of the properties of the comparative statics. One exceptional paper is concerned with these issues. Kaneda and Matsui (2003) consider an $n$ oligopoly-firm model with general (non-linear) demand and cost functions in which each firm's objective is to maximize the weighted average of profit and a general function representing alternative objectives such as revenue, market share, and so on. They then investigate the impact that the weights assigned to the alternative objectives have on the outputs and profits of the oligopoly firms in equilibrium. Nevertheless, the authors assume not only $n$ symmetric oligopoly firms but also conditions that are quite similar to Hahn's condition as well as seemingly ad-hoc conditions on the function representing the alternative objectives. These assumptions ensure the existence of a unique Nash equilibrium.

The principal motivation of this paper is to provide weaker but more general conditions for the existence and uniqueness of a Cournot-Nash equilibrium in such oligopoly models. We set up a Cournot oligopoly model composed of $n$ heterogeneous firms, each of which maximizes a different weighted average of profit and alternative, non-profit objectives, where the alternative objectives may include revenue, production volumes, cost, market share, or perworker profits. ${ }^{1}$ Following Kaneda and Matsui (2003), we adopt a general objective function to represent the alternative objectives not only because of its generality but also because of its flexibility. Using their weighted sum formulation for the different objective functions allows us to encompass various types of alternative objective functions for oligopoly firms, ranging from a purely profit-maximizing oligopoly firm to a purely non-profit-maximizing firm.

The most important new contribution of this paper is that we adopt the share function approach suggested by Cornes and Hartley $(2005,2011)$ to investigate the existence, uniqueness,

\footnotetext{
${ }^{1}$ To our best knowledge, the unpublished paper by Kaneda and Matsui (2003) is the first to introduce such a formulation. The resulting fairly complicated and restrictive technical conditions not only limit the applicability of their model but also obscure the main messages of their model.
} 
stability, and comparative statics properties of the Cournot-Nash equilibrium in the oligopoly game in which each oligopoly firm has the weighted average objective function stated above. This share function approach is not only simple but also powerful in handling these issues in a systematic and unified way. Irrespective of the form of the firm's objective function, this approach provides a general condition for the existence of a unique Cournot-Nash equilibrium. Another advantage of this approach is that it easily allows for many heterogeneous oligopoly firms, which is a generalization of the symmetric oligopoly game analyzed by Kaneda and Matsui (2003). Although the existing literature on profit-maximizing oligopoly models has commonly assumed Hahn's condition in order to prove the existence of an equilibrium, it is well recognized that this canonical condition is neither sufficient nor necessary for the existence of a unique Cournot-Nash equilibrium in the oligopoly model with strategic delegation. In contrast, using the share function approach of Cornes and Hartley, we not only provide a condition for the existence of a unique Cournot-Nash equilibrium in strategically delegated oligopoly models with general demand and cost functions, but we also identify the extent to which Hahn's condition is useful in signing comparative statics with respect to an idiosyncratic change in a parameter affecting only one specific firm in these oligopoly models. Kaneda and Matsui (2003) make several specific assumptions on the alternative objective function, whereas the share function approach of Cornes and Hartley enables us to show that Kaneda and Matsui's extra conditions are redundant. Moreover, Cornes and Hartley's approach provides the almost minimum set of conditions for the existence, uniqueness, and comparative statics properties in the Cournot oligopoly game in which each firm has the weighted sum formulation of the objective functions, as long as the weighted-sum objective functions retain the structure of aggregative games. We are especially concerned with how the different weights assigned to the alternative objectives of the different oligopoly firms affect the profiles of their outputs and profits in equilibrium.

The reminder of the paper is organized as follows. In Section 2, we present a basic oligopoly model in which each firm maximizes the weighted average of profit and another objective, such as revenue, output, cost, market share, or per-worker profits. We identify the general conditions for the existence and uniqueness of a Cournot-Nash equilibrium in this oligopoly 
model. In Section 3, using a comparative statics analysis of this oligopoly model with respect to an idiosyncratic change in a parameter that only affects a specific firm, we investigate how different weights affect the profiles of the outputs and profits of oligopoly firms in equilibrium. In Section 4, we investigate the conditions for stability of a Cournot-Nash equilibrium in this oligopoly model. In Section 5, we apply the share function approach to oligopoly models with more than two objectives and non-linear managerial contracts. In Section 6, we present concluding remarks.

\section{The Analysis}

\subsection{The Model}

We assume that there are $n$ potential producers of a homogeneous product, indexed by $i=$ $1,2, \ldots, n$, in Cournot oligopoly, but the set of active firms (i.e., firms producing positive output) will be determined endogenously. ${ }^{2}$ Firms simultaneously choose their own output. The inverse demand function is given by $P=P(X)$, where $P$ is the price, $x_{i}$ is the output of firm $i$, and $X=\sum_{j=1}^{n} x_{j}$ is the industry output.

Define the profit function of firm $i$ as follows:

$$
\pi_{i}\left(x_{i}, X\right)=P(X) x_{i}-C_{i}\left(x_{i}\right)
$$

We further define the true objective function of firm $i$, which will be the main focus of our analysis, as

$$
\begin{aligned}
\Pi_{i}\left(x_{i}, X, \theta_{i}\right) & \equiv\left(1-\theta_{i}\right) \pi\left(x_{i}, X\right)+\theta_{i} F^{i}\left(x_{i}, X\right) \\
& =\left(1-\theta_{i}\right)\left[P(X) x_{i}-C_{i}\left(x_{i}\right)\right]+\theta_{i} F^{i}\left(x_{i}, X\right)
\end{aligned}
$$

where $\theta_{i} \in(0,1)$ is a weight assigned to the alternative objective. Note that when $\theta_{i}=0$, firm

\footnotetext{
${ }^{2}$ This assumption does not imply that the number of firms is endogenously determined through the entry of new firms until profits are driven to zero but rather that each firm may be an active supplier depending on the market price of output and its cost function.
} 
$i$ is a profit maximizer. Without loss of generality, we assume that $\theta_{1}<\theta_{2}<\cdots<\theta_{n}$. A lower value of $\theta_{i}$ implies that the firm puts more weight on profits. The function $F^{i}($.$) represents$ the alternative objectives such as sales, production volumes, and so forth. In this paper, we focus on the following alternative objectives.

1. Revenue: $F^{i}\left(x_{i}, X\right) \equiv P(X) x_{i}$,

2. Output: $F^{i}\left(x_{i}, X\right) \equiv x_{i}$,

3. Market share: $F^{i}\left(x_{i}, X\right) \equiv x_{i} / X$,

4. Negative of cost: $F^{i}\left(x_{i}, X\right) \equiv-C_{i}\left(x_{i}\right)$,

5. Profit per worker: $F^{i}\left(x_{i}, X\right) \equiv \frac{P(X) x_{i}-C_{i}\left(x_{i}\right)}{N\left(x_{i}\right)}$.

Assume that

A.1 $\Pi_{i}\left(x_{i}, X, \theta_{i}\right) \in C^{2}$ for $\forall i \in I$, where $I$ is the set of firms (assumed to be finite).

The first-order condition associated with the maximization of (2) is given by

$$
\frac{\partial \prod_{i}\left(x_{i}, X, \theta_{i}\right)}{\partial x_{i}}=\left(1-\theta_{i}\right)\left[P^{\prime}(X) x_{i}+P(X)-C_{i}^{\prime}\left(x_{i}\right)\right]+\theta_{i}\left[F_{1}^{i}+F_{2}^{i}\right] \leq 0,
$$

with equality if $x_{i}>0$, where $\theta_{i}$ is a given positive parameter, and $F_{1}^{i} \equiv \partial F^{i}\left(x_{i}, X\right) / \partial x_{i}$ and $F_{2}^{i} \equiv \partial F^{i}\left(x_{i}, X\right) / \partial X$. We denote the middle expression in $(3)$ as $\gamma_{i}\left(x_{i}, X, \theta_{i}\right)$, which represents marginal profit.

\subsection{Existence and Uniqueness}

Cornes and Hartley $(2005,2011)$ further made the following assumptions in order to ensure the existence and uniqueness of Nash equilibria in pure strategies:

A.2 (i) There exists at least one firm, say firm $i \in I$, such that for some $x_{i}>0,{ }^{3}$

$$
\Pi_{i}\left(x_{i}, x_{i}, \theta_{i}\right)>\Pi_{i}\left(0,0, \theta_{i}\right)
$$

(ii) There exists a $u_{i} \in R^{+}$such that all strategies $x_{i}>u_{i}$ are strictly dominated. ${ }^{4}$

\footnotetext{
${ }^{3}$ This assumption implies that since at least one firm can make positive monopoly profits, the possibility of a Nash equilibrium in which all firms choose zero output is ruled out, and, thus, the sum of the respective share functions defined later exceeds or equals one at some level of industry output.

${ }^{4}$ Assumption A.2 will be replaced with A.6 later in the context of Cournot oligopoly competition.
} 
A.3 For $\forall i \in I$, if $\left(x_{i}, X\right)$ satisfies $0<x_{i}<X$ and $\gamma_{i}\left(x_{i}, X, \theta_{i}\right)=0$, then

$$
\frac{\partial \gamma_{i}\left(x_{i}, X, \theta_{i}\right)}{\partial x_{i}}<0
$$

where

$$
\frac{\partial \gamma_{i}\left(x_{i}, X, \theta_{i}\right)}{\partial x_{i}} \equiv\left(1-\theta_{i}\right)\left[P^{\prime}(X)-C_{i}^{\prime \prime}\left(x_{i}\right)\right]+\theta_{i}\left[F_{11}^{i}+F_{12}^{i}\right]
$$

and $F_{11}^{i} \equiv \partial^{2} F^{i}\left(x_{i}, X\right) / \partial x_{i}^{2}$ and $F_{21}^{i} \equiv \partial^{2} F^{i}\left(x_{i}, X\right) / \partial X \partial x_{i}$.

A.4 For $\forall i \in I$, if $\left(x_{i}, X\right)$ satisfies $0<x_{i}<X$ and $\gamma_{i}\left(x_{i}, X, \theta_{i}\right)=0$, then

$$
x_{i} \frac{\partial \gamma_{i}\left(x_{i}, X, \theta_{i}\right)}{\partial x_{i}}+X \frac{\partial \gamma_{i}\left(x_{i}, X, \theta_{i}\right)}{\partial X}<0
$$

where

$$
\frac{\partial \gamma_{i}\left(x_{i}, X, \theta_{i}\right)}{\partial X} \equiv\left(1-\theta_{i}\right)\left[P^{\prime \prime}(X) x_{i}+P^{\prime}(X)\right]+\theta_{i}\left[F_{12}^{i}+F_{22}^{i}\right],
$$

and

$$
F_{12}^{i} \equiv \partial^{2} F^{i}\left(x_{i}, X\right) / \partial x_{i} \partial X \text { and } F_{22}^{i} \equiv \partial^{2} F^{i}\left(x_{i}, X\right) / \partial X_{i}^{2}
$$

A.5 For $\forall i \in I$, if $\left(x_{i}, X\right)$ satisfies $0<x_{i}<X$ and $\gamma_{i}\left(x_{i}, X, \theta_{i}\right)=0$, then ${ }^{5}$

$$
\frac{\partial \gamma_{i}\left(x_{i}, X, \theta_{i}\right)}{\partial X}<0
$$

To understand the implications of $\mathbf{A . 3}$ and $\mathbf{A . 4}$, we need to understand the concepts of the replacement and share functions. When firm $i$ produces positive output, that is, when an interior solution exists, then since $\gamma_{i}($.$) is continuously differentiable and due to$ Assumption A.3, we can apply the implicit function theorem to the first-order condition $\gamma_{i}\left(\hat{x}_{i}, \hat{X}, \theta_{i}\right)=0$. As a result, there exists a continuously differentiable function $r_{i}: B \longmapsto A$ with $\gamma_{i}\left(r_{i}\left(X, \theta_{i}\right), X, \theta_{i}\right)=0$, where $A$ represents some open set containing $\hat{X}$ and $B$ represents some open set containing $\hat{x}_{i}$. We call such a function a replacement function $r_{i}\left(X, \theta_{i}\right)=$

${ }^{5}$ This assumption is stronger than necessary. Indeed, a weaker assumption such as

$$
\frac{\partial \gamma_{i}\left(x_{i}, X, \theta_{i}\right)}{\partial X} \leq 0
$$

is sufficient to prove the existence of a unique Nash equilibrium. However, in order to obtain definite comparative statics results, it is convenient to assume a strict inequality in A.5. 
$x_{i}\left(X, \theta_{i}\right)$, following Cornes and Hartley $(2005,2011) .{ }^{6}$ More formally, we can define the replacement function as follows:

Definition 1 If for any value of $X \geq 0$ there is a unique value $x_{i}^{B R} \equiv r_{i}\left(X, \theta_{i}\right)$ such that $x_{i}^{B R}$ is a best response to $X-x_{i}^{B R}$, then the function $r_{i}\left(X, \theta_{i}\right)$ is the replacement function of firm $i$.

For the reason stated later, when proving the uniqueness and existence of a CournotNash equilibrium, it may be more convenient to work with the share function rather than the replacement function. Firm $i$ 's share function is defined as follows:

Definition 2 Let firm $i$ have a replacement function $x_{i}=r_{i}\left(X, \theta_{i}\right)$. Then, for all $X>0$, the function $s_{i}\left(X, \theta_{i}\right) \equiv r_{i}\left(X, \theta_{i}\right) / X$ is the share function of firm $i$.

A Cournot-Nash equilibrium of the oligopoly model is an allocation at which $\sum_{j=1}^{n} s_{j}\left(X, \theta_{i}\right)=$ 1. More precisely, if (1) each firm's share function is continuous and monotonically decreasing when the share value is strictly positive, (2) all share functions approach or equal zero for larger $X$, and (3) each firm's share function has at least a unit upper bound, then it follows from the Intermediate Value Theorem that there exists a unique Cournot-Nash equilibrium in oligopolistic competition.

\footnotetext{
${ }^{6}$ The best-reply function $x_{i}=b_{i}\left(X_{-i}, \theta_{i}\right)$ implicitly satisfies the first-order condition (3); that is,

$$
\gamma_{i}\left(b_{i}\left(X_{-i}, \theta_{i}\right), X_{-i}+b\left(X_{-i}, \theta_{i}\right)\right)=0 .
$$
}

This produces

$$
b_{i}^{\prime}\left(X_{-i}, \theta_{i}\right)=-\frac{\partial \gamma_{i} / \partial X}{\left(\partial \gamma_{i} / \partial x_{i}\right)+\left(\partial \gamma_{i} / \partial X\right)} \gtreqless 0 \text { if and only if } \frac{\partial \gamma_{i}}{\partial X} \gtreqless 0,
$$

provided $\left(\partial \gamma_{i} / \partial x_{i}\right)+\left(\partial \gamma_{i} / \partial X\right)<0$ (which is immediately obtained from A.4; see Remark 2), which is consistent with the requirement of the second-order condition (i.e., strict concavity of the profit function;see Remark 2). Hence, the slope of the best-reply function depends solely on the sign of $\left(\partial \gamma_{i} / \partial X\right)$ so long as A.4 holds.

On the other hand, the slope of the replacement function $r_{i}\left(X, \theta_{i}\right)$ is given by

$$
r_{i}^{\prime}\left(X, \theta_{i}\right)=-\frac{\partial \gamma_{i} / \partial X}{\partial \gamma_{i} / \partial x_{i}}=\frac{b_{i}^{\prime}\left(X_{-i}, \theta_{i}\right)}{1+b_{i}^{\prime}\left(X_{i}, \theta_{i}\right)} \lesseqgtr 0 \text { if and only if } \frac{\partial \gamma_{i}}{\partial X} \gtreqless 0,
$$

provided $\partial \gamma_{i} / \partial x_{i}<0$ (i.e., A.3). Comparing the above two expressions reveals that the sign of $\partial \gamma_{i} / \partial X$ solely determines the slopes of both functions, given either A.3 or A.4. Alternatively, if A.3 and A.5 are assumed, then A.4 is satisfied, and thus both functions are negatively sloped. 
The condition for a monotonically decreasing share function (i.e., (1) is met) is given by

$$
\frac{d s_{i}\left(X, \theta_{i}\right)}{d X}=-\frac{x_{i} \frac{\partial \gamma_{i}\left(x_{i}, X, \theta_{i}\right)}{\partial x_{i}}+X \frac{\partial \gamma_{i}\left(x_{i}, X, \theta_{i}\right)}{\partial X}}{X^{2} \frac{\partial \gamma_{i}\left(x_{i}, X, \theta_{i}\right)}{\partial x_{i}}}<0 \text { if } \mathbf{A . 3} \text { and } \mathbf{A . 4} \text { hold. }
$$

Since the share function of firm $i$ is bounded above by some positive real number (which is implied by (i) in A.2), all share functions approach or equal zero for large enough $X$. Therefore, the same is true of the aggregate share function, and consequently, (2) is satisfied. Statement (ii) in A.2 implies that for an active equilibrium, where at least one firm produces a positive amount of output, the aggregate share function should be equal to or exceed one for some value of $X>0$, thus implying that (3) is satisfied.

There are several advantages to using the share function. The first is that it allows us to work with functions defined on the real line rather than a multi-dimensional best-reply mapping from $R^{n}$ to $R^{n}$. The second is that even if the replacement function is not monotonic, the share function may be monotonically decreasing; in this sense, the share function approach would potentially provide weaker conditions for the existence and uniqueness of a CournotNash equilibrium (see also footnote 6 ).

In order to ensure the existence and uniqueness of a Cournot-Nash equilibrium, much of the existing literature on Cournot oligopoly commonly assumes Hahn's condition, which is associated with dynamic stability (Hahn, 1962). Hahn's condition, $P^{\prime \prime}(X) X+P^{\prime}(X) \leq 0$ (i.e., the decreasing marginal revenue property) and $C^{\prime \prime}\left(x_{i}\right)-P^{\prime}(X)>0$, requires that as $X$ increases, the replacement function $x_{i}\left(X, \theta_{i}\right)$ decreases (see footnote 6 ). Nevertheless, Cornes and Hartley's condition (i.e., A.3 and A.4) allows for the possibility that $x_{i}\left(X, \theta_{i}\right)$ increases in response to an increase in $X_{-i}$. In other words, their condition allows that the best-reply function may be increasing or decreasing in $X$. For this reason, Cornes and Hartley's condition is significantly weaker than Hahn's condition in proving the existence and uniqueness of an equilibrium in the conventional Cournot oligopoly model (see Szidarovzsky and Yakowitz, 1977; Novshek, 1985). ${ }^{7}$

\footnotetext{
${ }^{7}$ For example, consider the constant elasticity of demand function $X=\alpha P^{-\varepsilon}$, which may not satisfy Hahn's condition (i.e., $\left.P^{\prime \prime}(X) x_{i}+P^{\prime}(X)<0\right)$.
} 
We can prove the following proposition in the Cournot oligopoly model with additional alternative objectives:

Proposition 1 Assume that $\boldsymbol{A . 1}-\boldsymbol{A} .4$ hold. There exists a unique Nash equilibrium in the Cournot oligopoly game in which each firm maximizes (2).

Proof. The proof of Cornes and Hartley $(2005,2011)$ is here applicable with appropriate modifications such as (2) and (3).

Remark 1 Kaneda and Matsui (2003) have assumed the following conditions to ensure the existence of a unique Cournot-Nash equilibrium of their oligopoly model with identical cost functions and with additional alternative objectives, that is,

$$
\begin{gathered}
P^{\prime \prime}(X) X+P^{\prime}(X) \leq 0 \text { and } C^{\prime \prime}\left(x_{i}\right)-P^{\prime}(X)>0 \\
P^{\prime \prime}(X) x_{i}+2 P^{\prime}(X)-C^{\prime \prime}\left(x_{i}\right)<0
\end{gathered}
$$

For the other objective, $F$, they assume that

$$
F_{1} \leq 0, F_{12}+F_{22}<0 \text { and } F_{11}+2 F_{12}+F_{22}<0 \text {. }
$$

They claim that all these conditions together guarantee the unique existence of a Nash equilibrium, whereas our conditions (i.e., A.3 and $\boldsymbol{A}$.4) for existence and uniqueness are not only much simpler but also allow for heterogeneity of firms (i.e., heterogeneous cost functions).

Remark 2 We need not assume that the second-order condition is satisfied provided assumptions $\boldsymbol{A . 3}$ and $\boldsymbol{A . 4}$ hold. Indeed, since the second-order condition can be rewritten as

$$
\begin{gathered}
\frac{\partial^{2} \Pi_{i}\left(x_{i}, X, \theta_{i}\right)}{\partial x_{i}^{2}}=\frac{\partial \gamma_{i}\left(x_{i}, X, \theta_{i}\right)}{\partial x_{i}}+\frac{\partial \gamma_{i}\left(x_{i}, X, \theta_{i}\right)}{\partial X} \\
=X^{-1}\left[\left(X-x_{i}\right) \frac{\partial \gamma_{i}\left(x_{i}, X, \theta_{i}\right)}{\partial x_{i}}+x_{i} \frac{\partial \gamma_{i}\left(x_{i}, X, \theta_{i}\right)}{\partial x_{i}}+X \frac{\partial \gamma_{i}\left(x_{i}, X, \theta_{i}\right)}{\partial X}\right]<0,
\end{gathered}
$$

it immediately follows that $\boldsymbol{A} .3$ and $\boldsymbol{A . 4}$ imply the second-order condition (8). On the other 
hand, since the second-order condition (8) can be rewritten as follows:

$$
\begin{gathered}
\frac{\partial \gamma_{i}\left(x_{i}, X\right)}{\partial x_{i}}+\frac{\partial \gamma_{i}\left(x_{i}, X\right)}{\partial X}= \\
\left(1-\theta_{i}\right)\left[P^{\prime}(X)-C_{i}^{\prime \prime}\left(x_{i}\right)\right]+\theta_{i}\left[F_{11}^{i}\left(x_{i}, X\right)+F_{21}^{i}\left(x_{i}, X\right)\right]+ \\
\left(1-\theta_{i}\right)\left[P^{\prime \prime}(X) x_{i}+P^{\prime}(X)\right]+\theta_{i}\left[F_{12}^{i}\left(x_{i}, X\right)+F_{22}^{i}\left(x_{i}, X\right)\right],
\end{gathered}
$$

it is readily seen from (9) that the conditions postulated by Kaneda and Matsui (2003) (i.e., (6) and (7) in Remark 1) also provide the second-order condition.

\section{Comparative Statics}

In this section, we investigate the comparative statics properties of Cournot oligopoly models with a variety of additional alternative objectives (i.e., the function $F($.$) ) that have appeared$ in the literature on oligopolies with strategic delegation and mixed oligopolies, as stated in the introduction. Since the resulting weighted average between pure profit maximization and non-profit maximization can be viewed as a reduced-form objective function at the second stage of the two-stage delegation game analyzed by VFJS, we do not undertake a full analysis of such a two-stage game. Instead, in what follows, we focus on the reduced-form objective function (2), into which the delegation decision has been already incorporated.

Cornes and Hartley $(2005,2011)$ show that in a Cournot oligopoly game, an idiosyncratic change in the payoff functions (i.e., profit functions) of a specific firm that leads the firm to increase its own output also leads to an increase in the total output of the industry, although other firms may respond by increasing or decreasing their outputs. We shall refer to a firm in a game with a unique Nash equilibrium as active if it chooses a positive strategy in that equilibrium; an inactive firm chooses zero. With some slight modifications, we will use the following proposition:

Proposition 2 [Theorem 4.2 of Cornes and Hartley (2005) and Theorem 10 of Cornes and Hartley (2011)] Let $G^{1}$ and $G^{2}$ be aggregative games with the same (finite) set of active firms, I, and the same profits for all firms except $i^{\prime} \in I$. Suppose that $\boldsymbol{A . 1}$ and $\boldsymbol{A . 3}$ hold for all 
firms and that $G^{1}$ and $G^{2}$ both have (unique) Nash equilibria: $\left(\hat{x}_{1}^{1} \cdot \hat{x}_{2}^{1}, \ldots, \hat{x}_{n}^{1}\right)$ and $\left(\hat{x}_{1}^{2} . \hat{x}_{2}^{2}, \ldots, \hat{x}_{n}^{2}\right)$. Suppose further that, for any $\left(x_{i}, X\right)$ satisfying $0<x_{i}<X$, we have

$$
\gamma_{i^{\prime}}^{1}\left(x_{i^{\prime}}, X\right)<\gamma_{i^{\prime}}^{2}\left(x_{i^{\prime}}, X\right) \text { and } \frac{\partial}{\partial X} \Pi_{i}\left(x_{i}, X\right)<0(>0) \text { for all } i \in I
$$

If $i^{\prime}$ is inactive in $G^{2}$, then $\left(\hat{x}_{1}^{1}, \hat{x}_{2}^{1}, \ldots, \hat{x}_{n}^{1}\right)=\left(\hat{x}_{1}^{2}, \hat{x}_{2}^{2}, \ldots, \hat{x}_{n}^{2}\right)$. Otherwise,

1. $\hat{X}^{2}>\hat{X}^{1}$, where $\hat{X}^{k} \equiv \sum_{j=1}^{n} \hat{x}_{j}^{k}$ for $k=1,2$,

2. firms in $I \backslash\left\{i^{\prime}\right\}$ that are active in $G^{1}$ are worse (better) off in $G^{2}$ than in $G^{1}$,

3. firms in $I \backslash\left\{i^{\prime}\right\}$ that are inactive in $G^{1}$ are inactive in $G^{2}$,

4. if $\Pi_{i^{\prime}}^{1}(0, X) \leq \Pi_{i^{\prime}}^{2}(0, X)$ for all $X>0$, then firm $i^{\prime}$ is better off in $G^{2}$ than in $G^{1}$, and

5. if $\boldsymbol{A} . \mathbf{5}$ holds for a player $i$ who is active in $G^{1}$, then $\hat{x}_{i}^{1}>\hat{x}_{i}^{2}$ for $i \in I \backslash\left\{i^{\prime}\right\}$, and $\hat{x}_{i^{\prime}}^{1}<\hat{x}_{i^{\prime}}^{2} 8$

As an immediate application of Proposition 2, coupled with the assumption of symmetric oligopoly firms, we can prove the following main proposition:

Proposition 3 Assume that all firms have identical cost functions and that A.1-A.4 hold. Suppose further that, for any $\left(x_{i}, X\right)$ satisfying $0<x_{i}<X$,

$$
\frac{\partial \gamma_{i}\left(x_{i}, X\right)}{\partial \theta_{i}}>0 \text { for all } i \in I
$$

and $0<\theta_{1}<\theta_{2}<\cdots<\theta_{n}<1$. Then

1. Total output increases,

2. If $\partial \Pi_{i}\left(x_{i}, X, \theta_{i}\right) / \partial X>0$, then $\Pi_{1}\left(\hat{x}_{1}, X, \theta_{1}\right) \leq \Pi_{2}\left(\hat{x}_{2}, X, \theta_{2}\right) \leq \cdots \leq \Pi_{n}\left(\hat{x}_{n}, X, \theta_{n}\right)$ and the inequality is strict if $s_{i}(X)>0$,

3. If $\partial \Pi_{i}\left(x_{i}, X, \theta_{i}\right) / \partial X<0$, then $\Pi_{1}\left(\hat{x}_{1}, X, \theta_{1}\right) \geq \Pi_{2}\left(\hat{x}_{2}, X, \theta_{2}\right) \geq \cdots \geq \Pi_{n}\left(\hat{x}_{n}, X, \theta_{n}\right)$ and the inequality is strict if $s_{i}(X)>0$, and

\footnotetext{
${ }^{8}$ Statement 5 of Proposition 5 is consistent with Proposition 2.4 and related results (see Corchón, 2001).
} 
4. If $\boldsymbol{A} . \mathbf{5}$ holds for an active player $i$, then $\hat{x}_{1}<\hat{x}_{2}<\cdots<\hat{x}_{n}$.

Conversely, suppose that, for any $\left(x_{i}, X\right)$ satisfying $0<x_{i}<X$,

$$
\frac{\partial \gamma_{i}\left(x_{i}, X, \theta_{i}\right)}{\partial \theta_{i}}<0 \text { for all } i \in I
$$

4. the results 1-4 hold with the inequalities reversed.

Proof. First, consider the case where $\partial \gamma_{i}\left(x_{i}, X\right) / \partial \theta_{i}>0$. To prove assertion 1 , suppose initially that $\theta_{1}=\theta_{2}=\cdots=\theta_{n}$. Since all firms are identical, they produce the same amount of output, i.e., $x_{1}=x_{2}=\cdots=x_{n}$. We denote this output profile of all firms as $x^{(0)}=\left(x_{1}^{(0)}, x_{2}^{(0)}, \cdots, x_{n}^{(0)}\right) \in R_{+}^{n}$, where the superscript represents the number of times the profile $\left(\theta_{1}, \theta_{2}, \cdots, \theta_{n}\right)$ is changed. Suppose now that an idiosyncratic increase in only the weight on firm 2 in the function $F, \theta_{2}$, occurs, which leads to the profile of weights with $\theta_{1}<\theta_{2}$ and $\theta_{1}=\theta_{3}=\cdots=\theta_{n}$. As shown in Figure 1, from statement 1 of Proposition 2, the total output, $X \equiv \sum_{j=1}^{n} x_{j}$, rises (this follows from statement 1 of Proposition 2). When A.5 holds, moreover, the resulting profile of outputs is given by $x^{(1)} \in R_{+}^{n}$ with $x_{1}^{(1)}<x_{2}^{(1)}$ and $x_{1}^{(1)}=x_{3}^{(1)}=\cdots=x_{n}^{(1)} \geq 0$. The first inequality is obtained by applying assertion 5 of Proposition 1, and the equalities stem from the identical first-order conditions for all $i$ except for firm 2:

$$
\begin{gathered}
\gamma_{i}\left(x_{i}, X, \theta_{i}\right)=(1-\theta)\left[P^{\prime}(X) x_{i}+P(X)-C^{\prime}\left(x_{i}\right)\right]+ \\
\theta\left[F_{1}\left(x_{i}, X\right)+F_{2}\left(x_{i}, X\right)\right] \leq 0, \text { for all } i \text { except for firm } 2
\end{gathered}
$$

with $\theta=\theta_{1}=\theta_{3}=\cdots=\theta_{n}$.

Starting from the previous order of the weights (i.e., $\theta_{1}<\theta_{2}$ and $\theta_{1}=\theta_{3}=\cdots=\theta_{n}$ ), suppose next an idiosyncratic increase in only the weight of firm $3, \theta_{3}$, which leads to a new profile of weights with $\theta_{1}<\theta_{2}<\theta_{3}$ and $\theta_{1}=\theta_{4}=\cdots=\theta_{n}$. As before, the total output is increased. When A.5 further holds, the output profile of all firms is given by $x^{(2)} \in R_{+}^{n}$ with $x_{1}^{(2)}<x_{2}^{(2)}<x_{3}^{(2)}$ and $x_{1}^{(2)}=x_{4}^{(2)}=\cdots=x_{n}^{(2)} \cdot x_{2}^{(2)}<x_{3}^{(2)}$ due to assertion 5 of Proposition 2 , as before, and $x_{1}^{(2)}<x_{2}^{(2)}$ because $x_{1}^{(1)}<x_{2}^{(1)}$ and because increasing the total output reduces 


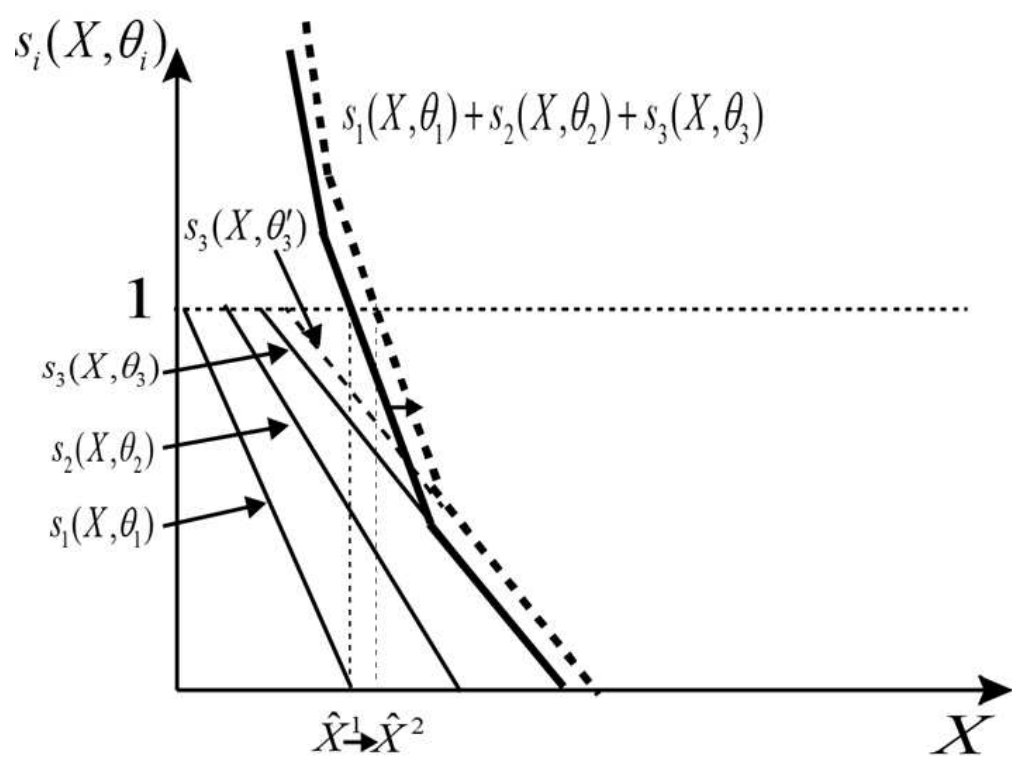

Figure 1: Total output increases in response to an increase in $\theta_{3}$ (i.e., $\theta_{3}<\theta_{3}^{\prime}$ ).

both outputs. In this way, by repeating the same argument as before $n-1$ times, we can prove that $x_{1}^{(n)}<x_{2}^{(n)}<\cdots<x_{n}^{(n)}$, and the total output continues to rise, which completes the proofs of statements (i) and (iv). Conversely, when $\partial \gamma_{i}\left(x_{i}, X, \theta_{i}\right) / \partial \theta_{i}<0$ (together with A.3 and A.5), the inequalities in assertions 1-3 are reversed (see Lemma 4.1 of Cornes and Hartley, 2005; Proposition 2.4 of Corchón, 2001). Assertions 1 and 2 of Proposition 3 can be immediately proven by the straightforward application of assertions 2 and 4 of Proposition 2 at every step of changing the profile of weights.

It should be noted that the results of Proposition 3 are based crucially on the assumption of identical cost functions. Since every oligopoly firm faces the same demand function, the heterogeneity among the firms stems from only the different weights assigned to the alternative objective functions. The symmetric assumption is quite important to rank profits as well as output among more than two firms. In general, only the response of the specific firm that is subject to an idiosyncratic shock affecting its own profit function can be signed; the responses of the other firms cannot be signed. More precisely, when, say, only $\theta_{2}$ increases, the outputs of all the firms except firm 2 fall, irrespective of whether the cost functions are identical or not. At the next step, on the other hand, when only $\theta_{3}$ increases, the outputs of all the firms except firm 3 unambiguously fall for the same reason as before. However, without the assumption of 
identical cost functions, we are not able to identify whether the resulting output of firm 2 is greater than that of firm 1 in equilibrium. Since the assumption of identical cost functions makes it possible to directly compare the first-order conditions of both firms, we can identify which firm has greater output.

Remark 3 To prove Proposition 3, Kaneda and Matsui (2003) have assumed either that $d F\left(x_{i}, X\right) / d x_{i}$ is positive whenever the (pure) marginal profit is nonnegative (i.e., $P^{\prime}(X) x_{i}+$ $P(X)-C^{\prime}\left(x_{i}\right) \geq 0$ ) or that if $d F\left(x_{i}, X\right) / d x_{i}$ is negative whenever the (pure) marginal profit is non-positive (i.e., $P^{\prime}(X) x_{i}+P(X)-C^{\prime}\left(x_{i}\right) \leq 0$ ). The first condition implies that the peak of the profit function, $P(X) x_{i}-C\left(x_{i}\right)$, is located to the left of the peak of the alternative objective function $F\left(x_{i}, X\right)$, whereas the second condition implies that their positions are reversed. In contrast, we do not need these conditions. Instead, the slope of the best-reply function matters in signing the comparative statics properties.

Up to this point, we have assumed general conditions for the existence and uniqueness of Nash equilibria independently of the detailed structure of the objective functions of a Cournot oligopoly firm. In the subsequent subsections, we will carry out comparative statics analysis exploiting the structure of the oligopolistic models with the various additional alternative objectives listed before.

A.6 $P(X)$ is a $C^{2}$ class function. There exists an $\xi \in(0, \infty)$ such that $P(X)=0$ holds for $X \in[\xi, \infty), P^{\prime}(X)<0$ for $X \in[0, \xi), X P(X) \rightarrow 0$ as $X \rightarrow 0$, and $P(X) \rightarrow 0$ as $X$ $\rightarrow \infty$. $C_{i}(0)$ is a $C^{2}$ class function. For $\forall i \in I, C_{i}^{\prime}\left(x_{i}\right) \geq 0$ for any $x_{i} \geq 0$, with strictly inequality if $x_{i}>0$, and $C_{i}(0)=0$.

A.7 (The strict inequality version of Hahn's condition) For $\forall i \in I$,

$$
P^{\prime \prime}(X) X+P^{\prime}(X)<0 \text { and } C_{i}^{\prime \prime}\left(x_{i}\right)-P^{\prime}(X)>0 .
$$

A.6 implies that the inverse demand function $P(X)$ must eventually fall below the average cost for larger $X$, and the corresponding levels of output are dominated by the choice of 
no output in the conventional Cournot oligopoly model as long as an additional alternative objective function $F($,$) is absent. It also implies that there exist positive monopoly profits at$ smaller levels of $X$ because the cost function continuously decreases to zero with $x_{i}$, whereas $P(X)$ eventually becomes positive with smaller levels of $X$. Taken together, A.6 ensures the fulfillment of $\mathbf{A . 2}$ as far as the standard Cournot oligopoly model without alternative objectives is concerned.

\section{$3.1 \quad$ Revenue}

VFJS consider the oligopoly model with delegation in which the manager's incentive contract consists of a linear combination of profits and sales revenue. In this case, each oligopoly firm maximizes the delegated objective function:

$$
\Pi_{i}^{R}\left(x_{i}, X, \theta_{i}\right) \equiv\left(1-\theta_{i}\right)\left[P(X) x_{i}-C\left(x_{i}\right)\right]+\theta_{i} P(X) x_{i} .
$$

In what follows, we assume that all firms have identical cost functions. i.e., $C\left(x_{i}\right)=C_{i}\left(x_{i}\right)$ for $\forall i \in I$. The first-order condition for profit maximization is given by

$$
\begin{aligned}
\gamma_{i}^{R}\left(x_{i}, X, \theta_{i}\right) & \equiv\left(1-\theta_{i}\right)\left[P^{\prime}(X) x_{i}+P(X)-C^{\prime}\left(x_{i}\right)\right]+\theta_{i}\left[P^{\prime}(X) x_{i}+P(X)\right] \\
& \equiv P^{\prime}(X) x_{i}+P(X)-\left(1-\theta_{i}\right) C^{\prime}\left(x_{i}\right) \leq 0
\end{aligned}
$$

where $\gamma_{i}^{R}\left(x_{i}, X, \theta_{i}\right)$ stands for the marginal profit function of firm $i$ as a function of $x_{i}$ and $X$, given a $\theta_{i}$.

To prove existence and uniqueness, we need to assume that A.3 and A.4 hold, i.e.,

$$
\frac{\partial \gamma_{i}^{R}\left(x_{i}, X, \theta_{i}\right)}{\partial x_{i}}=P^{\prime}(X)-\left(1-\theta_{i}\right) C^{\prime \prime}\left(x_{i}\right)<0
$$


and

$$
\begin{gathered}
x_{i} \frac{\partial \gamma_{i}^{R}\left(x_{i}, X, \theta_{i}\right)}{\partial x_{i}}+X \frac{\partial \gamma_{i}^{R}\left(x_{i}, X, \theta_{i}\right)}{\partial X}= \\
x_{i}\left[P^{\prime}(X)-\left(1-\theta_{i}\right) C^{\prime \prime}\left(x_{i}\right)\right]+X\left[P^{\prime \prime}(X) x_{i}+P^{\prime}(X)\right]<0 .
\end{gathered}
$$

In addition, it is easy to see that A.2 is satisfied under A.6 (A.1 is trivially satisfied); consequently, Proposition 1 holds. Moreover, it can be verified that under A.6

$$
\begin{aligned}
\frac{\partial \gamma_{i}^{R}\left(x_{i}, X, \theta_{i}\right)}{\partial \theta_{i}} & =C^{\prime}\left(x_{i}\right) \geq 0, \\
\frac{\partial \Pi_{i}^{R}\left(x_{i}, X, \theta_{i}\right)}{\partial X} & \equiv\left(1-\theta_{i}\right) P^{\prime}(X) x_{i}+\theta_{i} P^{\prime}(X) x_{i}=P^{\prime}(X) x_{i}<0, \\
\Pi_{i}^{R}\left(0, X, \theta_{i}\right) & =0=\Pi_{i}^{R}\left(0, X, \theta_{j}\right) \text { for all } X \text { and } \theta_{i}<\theta_{j},
\end{aligned}
$$

but

$$
\frac{\partial \gamma_{i}^{R}\left(x_{i}, X, \theta_{i}\right)}{\partial X}=P^{\prime \prime}(X) x_{i}+P^{\prime}(X) \gtreqless 0 .
$$

Taken together, under A.3, A.4, and A.6, it turns out not only that a unique CournotNash equilibrium exists, but also that $\Pi_{1}^{R}\left(\hat{x}_{1}, X, \theta_{1}\right) \geq \Pi_{2}^{R}\left(\hat{x}_{2}, X, \theta_{2}\right) \geq \cdots \geq \Pi_{n}^{R}\left(\hat{x}_{n}, X, \theta_{n}\right)$ (the inequality is strict if firm $i$ is active), and the total output falls since (14) and (15) hold (recall Proposition 3).

Taking another set of assumptions, if Hahn's condition A.7, together with A.6, is assumed, then A.3 and A.5 are satisfied (see (12) and (13)), thus ensuring the existence and uniqueness of the equilibrium and, moreover, that the sign of $\partial \gamma_{i}^{R}\left(x_{i}, X, \theta_{i}\right) / \partial X$ in (16) is negative; consequently, we obtain an increasing order of outputs across active firms (i.e., $\hat{x}_{1}<\hat{x}_{2}<\cdots<$ $\left.\hat{x}_{n}\right)$. Notably, different from Kaneda and Matsui (2003), without imposing any further specific conditions on the function $F\left(x_{i}, X\right)$, we can identify definite comparative statics responses with respect to the profits as well as the outputs of all firms. In short, Cornes and Hartley's condition (i.e., A.3 and A.4) enables us to highlight how and to what extent Hahn's condition (i.e., A.7) is effective in carrying out a comparative statics analysis and existence proof. 
Moreover, although the conditions that Kaneda and Matsui (2003) impose on the function $F\left(x_{i}, X\right)$ (i.e., (7) in Remark 1) mask such a relationship, Cornes and Hartley's condition reveal that these conditions imposed on $F\left(x_{i}, X\right)$ are clearly redundant.

\subsection{Output}

The second model is that the manager's incentive contract consists of a linear combination of profits and units sold (i.e., output), as considered by Vickers (1985) and Stewart (1992). In this case, the manager's objective function for oligopoly firm $i$ is expressed by:

$$
\Pi_{i}^{O}\left(x_{i}, X, \theta_{i}\right) \equiv\left(1-\theta_{i}\right)\left[P(X) x_{i}-C\left(x_{i}\right)\right]+\theta_{i} x_{i}
$$

The first-order condition for profit maximization is given by

$$
\gamma_{i}^{O}\left(x_{i}, X, \theta_{i}\right) \equiv\left(1-\theta_{i}\right)\left[P^{\prime}(X) x_{i}+P(X)-C^{\prime}\left(x_{i}\right)\right]+\theta_{i} \leq 0 .
$$

To prove existence and uniqueness, we first assume that A.3 and A.4 hold; i.e.,

$$
\begin{gathered}
\frac{\partial \gamma_{i}^{O}\left(x_{i}, X, \theta_{i}\right)}{\partial x_{i}}=\left(1-\theta_{i}\right)\left[P^{\prime}(X)-C^{\prime \prime}\left(x_{i}\right)\right]<0, \\
x_{i} \frac{\partial \gamma_{i}^{R}\left(x_{i}, X, \theta_{i}\right)}{\partial x_{i}}+X \frac{\partial \gamma_{i}^{R}\left(x_{i}, X, \theta_{i}\right)}{\partial X}= \\
\left(1-\theta_{i}\right)\left[x_{i}\left(P^{\prime}(X)-C^{\prime \prime}\left(x_{i}\right)\right)+X\left(P^{\prime \prime}(X) x_{i}+P^{\prime}(X)\right)\right]<0 .
\end{gathered}
$$

In addition, since $\mathbf{A . 2}$ (as well as $\mathbf{A . 1}$ ) are trivially satisfied, the existence and uniqueness of the equilibrium follow from Proposition 1.

To see how an increase in $\theta_{i}$ affects the behavior of oligopoly firms, we differentiate (18) with respect to $\theta_{i}$ to yield

$$
\begin{aligned}
\frac{\partial \gamma_{i}^{O}\left(x_{i}, X, \theta_{i}\right)}{\partial \theta_{i}} & =-\left[P(X)+P^{\prime}(X) x_{i}-C^{\prime}\left(x_{i}\right)\right]+1 \\
& \geq \frac{\theta_{i}}{1-\theta_{i}}+1=\frac{1}{1-\theta_{i}}>0
\end{aligned}
$$


where the first inequality follows from (18). Furthermore, it turns out that under A.6

$$
\begin{gathered}
\frac{\partial \Pi_{i}^{O}\left(x_{i}, X, \theta_{i}\right)}{\partial X}=\left(1-\theta_{i}\right) P^{\prime}(X) x_{i} \leq 0, \forall i \in I, \\
\Pi_{i}^{O}\left(0, X, \theta_{i}\right)=0=\Pi_{i}^{O}\left(0, X, \theta_{j}\right) \text { for all } X \text { and } \theta_{i}<\theta_{j},
\end{gathered}
$$

and

$$
\frac{\partial \gamma_{i}^{O}\left(x_{i}, X, \theta_{i}\right)}{\partial X}=\left(1-\theta_{i}\right)\left[P^{\prime \prime}(X) x_{i}+P^{\prime}(X)\right] \gtreqless 0 .
$$

To sum up, under A.3, A.4, and A.6, we can prove not only that a unique Cournot-Nash equilibrium exists but also that total output increases and the profits decrease in order across all output-concerned oligopoly firms, as in the case of revenue-concerned oligopoly firms. Under

the alternative set of assumptions A.6 and A.7, on the other hand, $\partial \gamma_{i}^{R}\left(x_{i}, X, \theta_{i}\right) / \partial X<0$ is obtained in addition to the existence and unique of the equilibrium, thus implying an increasing order of outputs across firms due to statement 5 of Proposition 2. Hence, the output-concerned oligopoly firms respond to different weights on the alternative objectives in the exact same way as the revenue-concerned oligopoly firms without the additional assumptions imposed on $F($.$) .$

\subsection{Negative of Cost}

Private firms in the most energy-intensive sectors, such as airlines and transport and delivery companies, are very concerned about higher oil prices. The regulation of public firms is sometimes based on cost observations because regulators do not know a firm's true cost. Baron and Besanko (1984) and Laffont and Tirole (1986) derive the optimal incentive scheme or contract that negatively depends on the costs reported by public firms. This incentive scheme encourages the manager to reduce the cost of production. In this case, the manager's objective function for oligopoly firm $i$ is expressed by:

$$
\Pi_{i}^{C}\left(x_{i}, X, \theta_{i}\right) \equiv\left(1-\theta_{i}\right)\left[P(X) x_{i}-C\left(x_{i}\right)\right]-\theta_{i} C\left(x_{i}\right)
$$


The first-order condition for profit maximization is given by

$$
\begin{aligned}
\gamma_{i}^{C}\left(x_{i}, X, \theta_{i}\right) & \equiv\left(1-\theta_{i}\right)\left[P^{\prime}(X) x_{i}+P(X)-C^{\prime}\left(x_{i}\right)\right]-\theta_{i} C^{\prime}\left(x_{i}\right) \\
& =\left(1-\theta_{i}\right)\left[P^{\prime}(X) x_{i}+P(X)\right]-C^{\prime}\left(x_{i}\right) \leq 0
\end{aligned}
$$

Since A.2 is also trivially satisfied under A.6, and assuming that A.3 and A.4 hold, i.e.,

$$
\frac{\partial \gamma_{i}^{C}\left(x_{i}, X, \theta_{i}\right)}{\partial x_{i}}=\left(1-\theta_{i}\right) P^{\prime}(X)-C^{\prime \prime}\left(x_{i}\right)<0
$$

and

$$
\begin{gathered}
x_{i} \frac{\partial \gamma_{i}^{R}\left(x_{i}, X, \theta_{i}\right)}{\partial x_{i}}+X \frac{\partial \gamma_{i}^{R}\left(x_{i}, X, \theta_{i}\right)}{\partial X}= \\
x_{i}\left[\left(1-\theta_{i}\right) P^{\prime}(X)-C^{\prime \prime}\left(x_{i}\right)\right]+X\left[P^{\prime \prime}(X) x_{i}+P^{\prime}(X)\right]<0,
\end{gathered}
$$

we can prove the existence of a unique Cournot-Nash equilibrium due to Proposition 1.

To see how an increase in $\theta_{i}$ affects the behavior of oligopoly firms, we differentiate (25) with respect to $\theta_{i}$ to yield

$$
\frac{\partial \gamma_{i}^{C}\left(x_{i}, X, \theta_{i}\right)}{\partial \theta_{i}}=-\left[P^{\prime}(X) x_{i}+P(X)\right] \leq 0
$$

where the inequality follows from (25). Furthermore, it turns out that under A.6

$$
\begin{gathered}
\frac{\partial \Pi_{i}^{C}\left(x_{i}, X, \theta_{i}\right)}{\partial X}=\left(1-\theta_{i}\right) P^{\prime}(X) x_{i} \leq 0, \forall i \in I, \\
\Pi_{i}^{C}\left(0, X, \theta_{i}\right)=0=\Pi_{i}^{C}\left(0, X, \theta_{j}\right) \text { for all } X \text { and } \theta_{i}<\theta_{j},
\end{gathered}
$$

and

$$
\frac{\partial \gamma_{i}^{C}\left(x_{i}, X, \theta_{i}\right)}{\partial X}=\left(1-\theta_{i}\right)\left[P^{\prime \prime}(X) x_{i}+P^{\prime}(X)\right] \gtreqless 0
$$

Taken together, it turns out that under A.3, A.4, and A.6, a unique Cournot-Nash equilibrium exists, but the total output of the industry falls, and thus we see that an increasing order 


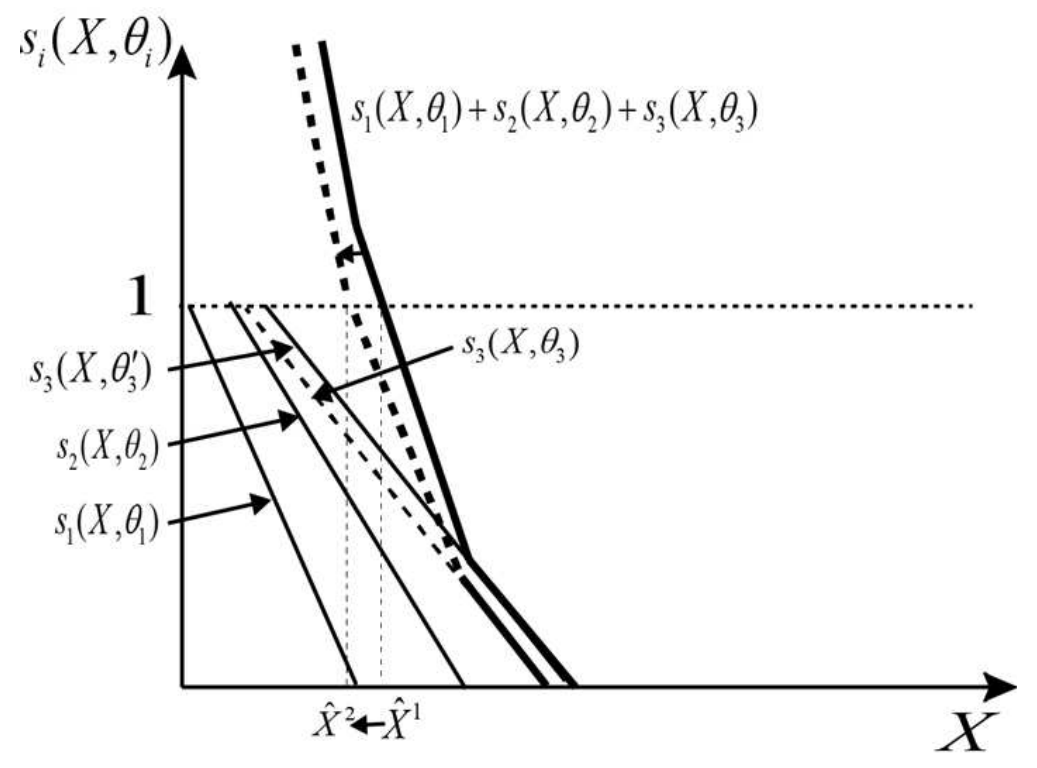

Figure 2: Total output decreases in response to an increase in $\theta_{3}$ (i.e., $\theta_{3}<\theta_{3}^{\prime}$ ).

of profits across all output-concerned oligopoly firms (i.e., $\Pi_{1}^{C}\left(\hat{x}_{1}, X, \theta_{1}\right)<\Pi_{2}^{C}\left(\hat{x}_{2}, X, \theta_{2}\right)<$ $\left.\cdots<\Pi_{n}^{C}\left(\hat{x}_{n}, X, \theta_{n}\right)\right)$ prevails due to $(29)$ and Proposition 3, unlike the cases of revenueconcerned and output-concerned oligopoly firms. Moreover, it follows from (28) that although under A.6 and A.7 $\partial \gamma_{i}^{C}\left(x_{i}, X, \theta_{i}\right) / \partial X<0$ is obtained, a decreasing order of outputs across firms emerges (see Corchón, 2001). ${ }^{9}$ The intuition behind these reversed results is clear. The effect of increasing the weight $\theta_{i}$ reduces the marginal profit of firm $i$ (see $(28)$ ), which is different from the revenue- and output-concerned oligopoly firms. Graphically, since the decreased marginal profit of firm $i$ shifts the aggregate share function to the left, thus resulting in a lower level of the total industry output, as illustrated in Figure 2.

\subsection{Market Share}

Jansen et al. (2007) and Ritz (2008) consider a delegation game in which the manager's incentive contract is written as a linear combination of profits and market share. In this case, the manager's objective function can be expressed by:

\footnotetext{
${ }^{9}$ Since

$$
P^{\prime}(X)-C^{\prime \prime}\left(x_{i}\right)<\left(1-\theta_{i}\right) P^{\prime}(X)-C^{\prime \prime}\left(x_{i}\right)<0
$$

Hahn's condition (i.e., $\left.P^{\prime}(X)-C^{\prime \prime}\left(x_{i}\right)<0\right)$ does not ensure the negativity of $\left(1-\theta_{i}\right) P^{\prime}(X)-C^{\prime \prime}\left(x_{i}\right)($ recall that $P^{\prime}(X)<0$, but the sign of $C^{\prime \prime}\left(x_{i}\right)$ is indeterminate). More precisely, we here have to make a slightly stronger assumption in that $\left(1-\theta_{i}\right) P^{\prime}(X)-C^{\prime \prime}\left(x_{i}\right)<0$ rather than Hahn's condition.
} 


$$
\Pi_{i}^{M}\left(x_{i}, X, \theta_{i}\right) \equiv\left(1-\theta_{i}\right)\left[P(X) x_{i}-C\left(x_{i}\right)\right]+\theta_{i}\left(x_{i} / X\right)
$$

The first-order condition for profit maximization is given by

$$
\gamma_{i}^{M}\left(x_{i}, X, \theta_{i}\right) \equiv\left(1-\theta_{i}\right)\left[P^{\prime}(X) x_{i}+P(X)-C^{\prime}\left(x_{i}\right)\right]+\theta_{i}\left(X-x_{i}\right) X^{-2} \leq 0
$$

As before, assuming that for $\forall i \in I \mathbf{A . 3}$ and A.4 hold, i.e.,

$$
\begin{gathered}
\frac{\partial \gamma_{i}^{M}\left(x_{i}, X, \theta_{i}\right)}{\partial x_{i}}=\left(1-\theta_{i}\right)\left[P^{\prime}(X)-C^{\prime \prime}\left(x_{i}\right)\right]-\theta_{i} \frac{1}{X^{2}}<0, \\
x_{i} \frac{\partial \gamma_{i}^{R}\left(x_{i}, X, \theta_{i}\right)}{\partial x_{i}}+X \frac{\partial \gamma_{i}^{R}\left(x_{i}, X, \theta_{i}\right)}{\partial X}= \\
x_{i}\left[P^{\prime}(X)-\left(1-\theta_{i}\right) C^{\prime \prime}\left(x_{i}\right)\right]+X\left[P^{\prime \prime}(X) x_{i}+P^{\prime}(X)\right]<0,
\end{gathered}
$$

and since A.2 is trivially satisfied, the existence and uniqueness of the equilibrium are guaranteed.

We differentiate $(32)$ with respect to $\theta_{i}$ to yield

$$
\begin{aligned}
\frac{\partial \gamma_{i}^{M}\left(x_{i}, X, \theta_{i}\right)}{\partial \theta_{i}} & =-\left[P^{\prime}(X) x_{i}+P(X)-C^{\prime}\left(x_{i}\right)\right]+\frac{X-x_{i}}{X^{2}} \\
& \geq \frac{\theta_{i}}{1-\theta_{i}} \frac{X-x_{i}}{X^{2}}+\frac{X-x_{i}}{X^{2}}>0,
\end{aligned}
$$

where the first inequality follows from (32). Furthermore, it follows from A.6 that

$$
\begin{gathered}
\frac{\partial \Pi_{i}^{M}\left(x_{i}, X, \theta_{i}\right)}{\partial X}=\left(1-\theta_{i}\right) P^{\prime}(X) x_{i}-\theta_{i}\left(x_{i} / X^{2}\right)<0, \forall i \in I \\
\Pi_{i}^{M}\left(0, X, \theta_{i}\right)=0=\Pi_{i}^{M}\left(0, X, \theta_{j}\right) \text { for all } X \text { and } \theta_{i}<\theta_{j},
\end{gathered}
$$

and

$$
\frac{\partial \gamma_{i}^{O}\left(x_{i}, X, \theta_{i}\right)}{\partial X}=\left(1-\theta_{i}\right)\left[P^{\prime \prime}(X) x_{i}+P^{\prime}(X)\right]+\theta_{i} \frac{2 x_{i}-X}{X^{3}} \gtreqless 0 .
$$


Under A.3, A.4, and A.6, we can obtain the same results as for revenue- and outputconcerned oligopoly firms. However, it is immediately seen from (36) that Hahn's condition no longer suffices to sign A.5, so that neither the comparative statics properties nor the existence of a unique Nash equilibrium is obtained. This result is due to the presence of an additional term arising from the alternative objective function $F($.$) , which is different from any of the$ previous oligopoly models.

\subsection{Labor-Managed Oligopoly}

Many authors investigate the interaction between profit-maximizing and labor-managed Cournot oligopolies, whereas Stewart (1992) considers a delegation game in a mixed oligopoly setting in which a labor-managed firm and a private firm compete with each other and the managers of both firms are concerned with profit, the surplus to workers, or output. We consider a mixed oligopoly model whose objective function is expressed by a linear combination of profit and the surplus to workers:

$$
\Pi_{i}^{L}\left(x_{i}, X, \theta_{i}\right) \equiv\left(1-\theta_{i}\right)\left[P(X) x_{i}-C\left(x_{i}\right)\right]+\theta_{i} \frac{P(X) x_{i}-C_{i}\left(x_{i}\right)}{N\left(x_{i}\right)}
$$

The first-order condition for profit maximization is given by

$$
\begin{gathered}
\gamma_{i}^{L}\left(x_{i}, X, \theta_{i}\right) \equiv\left(1-\theta_{i}\right)\left[P^{\prime}(X) x_{i}+P(X)-C^{\prime}\left(x_{i}\right)\right]+ \\
\theta_{i}\left\{\frac{P^{\prime}(X) x_{i}+P(X)-C^{\prime}\left(x_{i}\right)}{N\left(x_{i}\right)}-\frac{\left[P(X) x_{i}-C\left(x_{i}\right)\right] N^{\prime}\left(x_{i}\right)}{\left[N\left(x_{i}\right)\right]^{2}}\right\} \leq 0 .
\end{gathered}
$$

We assume that A.3 and A.4 hold, i.e.,

$$
\begin{gathered}
\frac{\partial \gamma_{i}^{L}\left(x_{i}, X, \theta_{i}\right)}{\partial x_{i}}=\left(1-\theta_{i}\right)\left[P^{\prime}(X)-C^{\prime \prime}\left(x_{i}\right)\right] \\
+\frac{\theta_{i}}{\left[N\left(x_{i}\right)\right]^{2}}\left\{\left[P^{\prime}(X)-C^{\prime \prime}\left(x_{i}\right)\right] N\left(x_{i}\right)-\left[P(X)+P^{\prime}(X) x_{i}-C^{\prime}\left(x_{i}\right)\right] N^{\prime}\left(x_{i}\right)\right. \\
\left.+\left[P(X)-C^{\prime}\left(x_{i}\right)\right] \frac{N^{\prime}\left(x_{i}\right)}{N\left(x_{i}\right)}\left[-\frac{1}{N\left(x_{i}\right)}+N^{\prime}\left(x_{i}\right)\right]-\left[P(X) x_{i}-C\left(x_{i}\right)\right] N^{\prime \prime}\left(x_{i}\right)\right\}<0 .
\end{gathered}
$$




$$
x_{i} \frac{\partial \gamma_{i}^{R}\left(x_{i}, X, \theta_{i}\right)}{\partial x_{i}}+X \frac{\partial \gamma_{i}^{R}\left(x_{i}, X, \theta_{i}\right)}{\partial X}<0
$$

Nevertheless, in spite of assuming A.6, $N^{\prime}\left(x_{i}\right)>0, N^{\prime \prime}\left(x_{i}\right)>0$, and $N\left(x_{i}\right)-x_{i} N^{\prime}\left(x_{i}\right)<0$ (see Remark 4 and Footnote 9), we cannot sign the following expressions:

$$
\begin{aligned}
\frac{\partial \gamma_{i}^{L}\left(x_{i}, X, \theta_{i}\right)}{\partial X} & =\left(1-\theta_{i}\right)\left[P^{\prime \prime}(X) x_{i}+P^{\prime}(X)\right]+\theta_{i}\left\{\frac{P^{\prime \prime}(X) x_{i}+P^{\prime}(X)}{N\left(x_{i}\right)}-\frac{P^{\prime}(X) x_{i} N^{\prime}\left(x_{i}\right)}{\left[N\left(x_{i}\right)\right]^{2}}\right\} \\
& =\left(1-\theta_{i}+\frac{\theta_{i}}{N\left(x_{i}\right)}\right)\left[P^{\prime \prime}(X) x_{i}+P^{\prime}(X)\right]-\theta_{i} \frac{P^{\prime}(X) x_{i} N^{\prime}\left(x_{i}\right)}{\left[N\left(x_{i}\right)\right]^{2}} \gtreqless 0,
\end{aligned}
$$

and

$$
\begin{gathered}
\frac{\partial \gamma_{i}^{L}\left(x_{i}, X, \theta_{i}\right)}{\partial \theta_{i}}=-\left[P^{\prime}(X) x_{i}+P(X)-C^{\prime}\left(x_{i}\right)\right] \\
+\frac{P(X)+P^{\prime}(X) x_{i}-C^{\prime}\left(x_{i}\right)}{N\left(x_{i}\right)}-\frac{\left[P(X) x_{i}-C^{\prime}\left(x_{i}\right)\right] N^{\prime}\left(x_{i}\right)}{\left[N\left(x_{i}\right)\right]^{2}} \gtreqless 0,
\end{gathered}
$$

whose inequality follows from (38). On the other hand, under A.6

$$
\frac{\partial \Pi_{i}^{L}\left(x_{j}, X, \theta_{i}\right)}{\partial X}=P^{\prime}(X) x_{i}\left[1-\theta_{i}+\frac{\theta_{i}}{N\left(x_{i}\right)}\right]<0
$$

and

$$
\Pi_{i}^{L}\left(0, X, \theta_{i}\right)=0=\Pi_{i}^{L}\left(0, X, \theta_{j}\right) \text { for all } X \text { and } \theta_{i}<\theta_{j}
$$

Taken together, under A.3, A.4, and A.6, the existence and uniqueness of the equilibrium are guaranteed due to Proposition 1. However, the order of the individual firms' profits as well as the total output may shift in either direction depending on the sign of $\partial \gamma_{i}^{L}\left(x_{i}, X, \theta_{i}\right) / \partial \theta_{i}$ in (42)), in spite of the negative sign of $\partial \Pi_{i}^{L}\left(x_{j}, X, \theta_{i}\right) / \partial X$ in (43). This ambiguous result stems from the fact that higher values of the weight $\theta_{i}$ move the reaction function of an individual firm (38) inwards or outwards depending on the sign of $\partial \gamma_{i}^{L}\left(x_{i}, X, \theta_{i}\right) / \partial \theta_{i}$. Even if $\mathbf{A . 5}$ is assumed (i.e., $\left.\partial \gamma_{i}^{L}\left(x_{i}, X, \theta_{i}\right) / \partial X<0\right)$, either result still emerges for the output ranking across firms depending on the sign of $\partial \gamma_{i}^{L}\left(x_{i}, X, \theta_{i}\right) / \partial \theta_{i}$.

As one may expect, Hahn's condition no longer serves in either proving the unique existence of an equilibrium or identifying comparative statics properties. Hence, in this model, either 
A.3 and A.4 (Cornes and Hartley's condition; 2005, 2012) or A.3 and A.5 (Corchón's condition, 2001) is quite essential to ensure the existence of the equilibrium and to derive comparative statics.

Remark 4 Kaneda and Matsui (2003) have assumed conditions such as $N^{\prime}\left(x_{i}\right)>0, N^{\prime \prime}\left(x_{i}\right)>$ 0 , and $N\left(x_{i}\right)-x_{i} N^{\prime}\left(x_{i}\right)<0$, together with Hahn's condition in (6), to ensure the existence of a Cournot-Nash equilibrium. The first two assumptions hold under a decreasing-returnsto-scale production function. ${ }^{10}$ In contrast, we can dispense with these assumptions to prove the existence of an equilibrium for labor-managed oligopoly firms by using the share function approach.

\section{Stability}

In this section, we investigate the global stability of the equilibria of the oligopoly game presented in the previous section. The assumption of stability is needed not only to sign the comparative statics properties of the oligopoly equilibrium but also to enable comparative statics analysis in the sense that the system automatically moves to a new Nash equilibrium over time after some exogenous shock occurs.

We focus on the Gradient Dynamics where each firm increases the value of its strategy if and only if its marginal profit is positive. A motivation for Gradient Dynamics is that firms attempt to increase their profits by moving in the direction given by the gradient of their profit functions:

$$
\dot{x}_{i}=\kappa_{i} \gamma_{i}\left(x_{i}, X, \theta_{i}\right) \text { for all } i \in I
$$

where $\kappa_{i}>0$ denotes the speed of response of $i, \gamma_{i}\left(x_{i}, X, \theta_{i}\right)$ corresponds to the marginal profit in $(3)$, and the initial point satisfies $\left(x_{1}(0), x_{2}(0), \ldots, x_{n}(0)\right)>0$. Alternatively, the dynamics can be expressed by Hahn-Novshek's best-reply dynamics:

$$
\dot{x}_{i}=\kappa_{i}\left[b_{i}\left(X_{-i}, \theta_{i}\right)-x_{i}\right] \text { for all } i \in I,
$$

\footnotetext{
${ }^{10}$ This assumption amounts to assuming that the production function of firm $i$ displays decreasing returnsto-scale. Indeed, denote such a production function as $x_{i}=f_{i}\left(N_{i}\right)$, with $f_{i}^{\prime}\left(N_{i}\right)>0$ and $f_{i}^{\prime \prime}\left(N_{i}\right)<0$. We obtain $d N / d x=1 / f^{\prime}\left(N_{i}\right)>0$ and $d^{2} N / d x^{2}=-f_{i}^{\prime \prime}\left(N_{i}\right) /\left[f^{\prime}\left(N_{i}\right)\right]^{2}>0$.
} 
provided each oligopoly firm has a well-defined best reply function, $b_{i}\left(X_{-i}, \theta_{i}\right)$. As shown below, the downward-sloping share function is not sufficient to demonstrate the stability of a Cournot-Nash equilibrium under both (44) and (45). We need a stronger condition such as A.5, which produces the following proposition:

Proposition 4 Suppose $\hat{x}=\left(\hat{x}_{1}, \hat{x}_{2}, \ldots, \hat{x}_{n}\right)$ is a non-critical Cournot-Nash equilibrium of a smooth aggregate game in which $\boldsymbol{A . 1}, \boldsymbol{A . 2}, \boldsymbol{A . 3}$, and $\boldsymbol{A . 5}$ hold for all firms. There exists a unique Cournot-Nash equilibrium that is asymptotically stable under the adjustment rule (44) or $(45)$.

The proof of Cornes and Hartley (2005) and Corchón (2001) is applicable here with appropriate modifications (2) and (3). This proof shows that a negative slope of the best-reply function (or equivalently, a replacement function that is decreasing in total output) is needed to ensure stability. Hence, condition A.5 (together with A.3) ensures not only the existence of a unique Nash equilibrium but also its stability, because it ensures that the best-reply function $b_{i}\left(X_{-i}, \theta_{i}\right)$ is decreasing in $X_{-i}$ (or equivalently, the replacement function, $r_{i}\left(X, \theta_{i}\right)$, is decreasing in $X$ ). Nevertheless, Hahn's condition still suffices to insure stability for the cases of the revenue-, output-, and cost-concerned oligopoly firms, whereas it does not help in signing $\partial \gamma_{i}^{L}\left(x_{i}, X, \theta_{i}\right) / \partial X$ (i.e., A.5) and thus does not ensure stability for the marketshare-concerned and labor-managed oligopoly firms. In light of these results, the use of A.5 to obtain definite comparative statics results might be justified to ensure the stability of the oligopoly model we have considered.

\section{Multiple Objectives and Non-linear Managerial Con- tracts}

In this section, we consider an oligopoly firm that has more than two objectives. For example, a public firm may have several objectives such as pure profit maximization, output maximization, revenue maximization, and so forth at the same time. The manger's incentive contract may be written as a weighted sum of more than two objectives. The true objective function of firm 
$i$ with multiple alternative objectives ( $m$ total objectives including pure profit maximization) is given by:

$$
\Pi_{i}\left(x_{i}, X, \Theta_{i}\right) \equiv \theta_{i 1}\left[P(X) x_{i}-C_{i}\left(x_{i}\right)\right]+\sum_{j=1}^{m} \theta_{i j} F^{i j}\left(x_{i}, X\right), \quad i=1,2, \ldots, n
$$

where the vector $\Theta_{i} \equiv\left(\theta_{i 1}, \theta_{i 2}, \cdots, \theta_{i m}\right) \in R_{+}^{m}$ represents the weights of firm $i$ assigned to the alternative objectives stated before with $\sum_{j=1}^{m} \theta_{i j}=1$, and $F^{i j}\left(x_{i}, X\right)$ represents the objective $j$ of firm $i$. The conditions to ensure the existence of a unique Cournot-Nash equilibrium in the oligopoly model with multiple objectives are once again given by A.3 and A.4 with appropriate modifications. Stability is also ensured by $\mathbf{A . 3}$ and A.5, even in the presence of the additional alternative objectives in (46). However, there is no prospect for the application of Hahn's condition to draw meaningful comparative statics results as well as to prove the existence of an equilibrium when oligopoly firms have such complicated objective functions. On the other hand, once we know the effect of changing $\theta_{i j}$ on the marginal profit (i.e., the sign of $\left.\partial \gamma_{i}\left(x_{i}, X, \Theta_{i}\right) / \theta_{i j}, j=1, . . m\right)$ and $\partial \Pi_{i}\left(x_{i}, X, \Theta_{i}\right) / \partial X, i=1, . . m$, we can unambiguously identify the effects on the profits and the outputs of firms under A.3, A.5, and A.6.

Another interesting extension is to consider a mixed oligopoly model in which several firms in the same market have different objectives. For example, the true objective function of one firm is the weighted average of profits and sale revenues, whereas other firms may have as an objective function the weighted average of different combinations such as profit and output, profit and market share, the surplus to workers and output, and so on. In such a mixed market, provided the marginal profit function of the respective oligopoly firms satisfies A.3, A.4, and A.6 (alternatively, A.3, A.5, and A.6), the existence of a unique Cournot-Nash equilibrium of this oligopoly competition can easily be guaranteed, and, moreover, stability is ensured by A.5.

Although we have focused on linear managerial contracts so far, we may consider a more general non-linear managerial incentive contract such as

$$
\Pi_{i}\left(x_{i}, X\right) \equiv B_{i}\left[F^{i 0}\left(x_{i}, X\right), F^{i 1}\left(x_{i}, X\right), \cdots, F^{i m}\left(x_{i}, X\right)\right], i=1,2, \ldots, n,
$$


where $F^{i 0}($.$) represents the pure profit purpose and F^{i j}\left(x_{i}, X\right)$ represents the alternative purposes. Since the manager receives a bonus according to this non-linear contract, she maximizes the above objective function in the second stage of the delegation game. In this case, the conditions for existence, uniqueness, comparative statics, and stability are the same as before, although Hahn's condition is no longer helpful in proving these issues. Since in this model there is no explicit parameter for the weights, we can alternatively investigate the effects on outputs and profits caused by other underlying basic parameters that characterize the structure of the contract or technological improvements in the cost, factor prices, output prices, and so on.

\section{Concluding Remarks}

In this paper, we investigate the existence and uniqueness of a Nash equilibrium in Cournot oligopoly models where firms maximize a weighted average of a pure profit-maximizing objective and an alternative, non-profit-maximizing objective. Hahn's condition does not in general serve in resolving these issues in these oligopoly models because the complexity of the objective functions prevents from a straightforward application of Hahn's condition. Under these circumstances, the conditions for the downward-sloping share function provided by Cornes and Hartley $(2005,2011)$ play a decisive role in deriving the existence, uniqueness, some comparative static properties, and stability for a Cournot-Nash equilibrium. More precisely, if we are only interested in the existence of a unique Nash equilibrium, assumptions A.3 and A.4 (which together imply a downward-sloping share function), coupled with either $\mathbf{A . 1}$ and A.2 or A.6, are sufficient to prove it. In other words, the share function approach would provide weaker and more powerful conditions to ensure the existence and uniqueness of the equilibrium in the Cournot oligopoly model with heterogeneous firms possessing complicated objective functions arising from, say, a strategic delegation game with an owner and a manager. It should be stressed that the strength of Cornes and Hartley's share function approach lies in the wider applicability and generality in the sense that it does not rely on the specific details of the model. 
Furthermore, Cornes and Hartley's share function approach also enables us to identify how and to what extent Hahn's condition, which is the most commonly used condition in the conventional Cournot oligopoly model without alternative, non-profit-maximizing objectives, serves in analyzing comparative statics and insuring the stability of a Cournot-Nash equilibrium. The downward-sloping best-reply function is ensured by Hahn's condition as long as the alternative objective of oligopoly firms is given by revenue, output, or cost. Nevertheless, Hahn's condition does not help us to identify comparative statics properties and to ensure stability in the cases of the market share-concerned or labor-managed oligopoly firms because the one-to-one relationship between Hahn's condition and A.5 fails to hold due to the complexity of the objective functions. ${ }^{11}$

The model and approach presented in this paper should be developed further in several directions. First of all, introducing product differentiation would make this oligopoly model and its results richer and more fruitful. We are particularly interested in understanding which forms of the consumers' utility functions generate aggregate games. To conduct this extension, we would have to apply the generalized aggregate game developed by Cornes and

\footnotetext{
${ }^{11}$ Unfortunately, the aggregative game approach is not useful for the model of Fumas (1992) and Miller and Pazgal (2002) in which the manager's incentive contract is based on a weighted sum of the firm's own profit and its rival's profits (or their average profits):

$$
\begin{gathered}
\Pi_{i}^{R P}\left(x_{1}, \ldots, x_{n}, X, \theta_{i}\right) \equiv\left(1-\theta_{i}\right) \pi_{i}\left(x_{i}, X\right)+\theta_{i}\left[\pi_{i}\left(x_{i}, X\right)-\frac{1}{n} \sum_{j=1}^{n} \pi_{j}\left(x_{i}, X\right)\right] \\
=\pi_{i}\left(x_{i}, X\right)+\theta_{i}\left[-\frac{1}{n} \sum_{j=1}^{n} \pi_{j}\left(x_{i}, X\right)\right] .
\end{gathered}
$$
}

It is easily seen that the above true profit function (in particular, the second term in $\Pi_{i}^{R P}($.$) ) depends on the$ profile of the other firms' outputs in addition to its own output and total output, which violates the definition of an aggregative game (see Cornes and Hartley, 2005, 2011).

On the other hand, in the literature on mixed oligopoly, a public firm is usually assumed to maximize social welfare, defined as the sum of consumer surplus and firm profit (see, e.g., De Fraja and Delbono, 1989; White, 1996). The true objective functions of those firms, $\Pi_{i}^{S}($.$) , depend also on the output choices of other$ firms (through social welfare) in addition to the firms' own output choices as well as the aggregative level of industry output such as

$$
\Pi_{i}^{S}\left(x_{1}, \ldots, x_{n}, X, \theta_{i}\right) \equiv\left(1-\theta_{i}\right)\left[P(X) x_{i}-C\left(x_{i}\right)\right]+\theta_{i} S W_{i}\left(x_{1}, \ldots, x_{n}, X\right),
$$

where

$$
S W\left(x_{1}, \ldots, x_{n}, X\right) \equiv \int_{0}^{X} P(q) d q-P(X) X+\sum_{j=1}^{n}\left[P(X) x_{j}-C\left(x_{j}\right)\right]=\int_{0}^{X} P(q) d q-\sum_{j=1}^{n} C\left(x_{j}\right),
$$

which clearly violates the definition of the aggregative game. 
Hartley (2012), which will be left as our future work. Another important research agenda is to investigate the effect of changes in tax, such as commodity taxes imposed on the market equilibrium price and output or corporate income taxes. In particular, comparing specific and ad valorem taxes would be an interesting research approach. The aggregate game approach certainly provides a powerful tool to analyze these comparative statics effects in a systematic way without complicated algebraic calculations. A more challenging research agenda would be to allow for some firms whose share functions are not monotonically decreasing. Nevertheless, as the number of firms having a monotonically declining share function becomes larger, such a non-monotonic effect would be neutralized so that the aggregate share function would have a unique intersection with the 45-degree line, thus ensuring the existence of a unique Nash equilibrium.

\section{References}

Baron, D.P. and Besanko, D. (1984) Regulation, asymmetric information, and auditing, Rand Journal of Economics 15, 75-92.

Cornes, R. and Hartley, R. (2005) The geometry of aggregative games, mimeo, University of Nottingham.

Cornes, R. and Hartley, R. (2011) Well-behaved aggregate games, personal.strath.ac.uk.

Cornes, R. and Hartley, R. (2012) Fully aggregative games, Economics Letters 116, 631-633.

Corchón, L.C. (2001) Theories of imperfectly comparative markets, Second edition Springer.

De Fraja, G. and Delbono, F. (1989) Alternative strategies of a public enterprise in oligopoly 41, Oxford Economic Papers 41, 302-311.

Fershtman, C., and Judd, K.L. (1987) Equilibrium incentives in oligopoly, American Economic Review 77, 927-940.

Fumas, V.S. (1992) Relative performance evaluation of management: The effects on industrial 
competition and risk sharing, International Journal of Industrial Organization 10, 473489.

Hahn, F. (1962) The stability of the Cournot oligopoly solution, Review of Economic Studies $29,329-533$.

Jansen, T., van Lier, A., and van Witteloostuijn, A. (2007) A note on strategic delegation: The market share case, International Journal of Industrial Organization 25, 531-539.

Kaneda, M. and Matsui, A. (2003) Do profit maximizers maximize profit?: Divergence of objective and result in oligopoly, mimeo, University of Tokyo.

Kolstad, C. and Mathiersen, L. (1987) Necessary and sufficient conditions for uniqueness of a Cournot equilibrium, Review of Economic Studies, 54, 681-690.

Laffont, J-J and Tirole, J. (1986) Using cost observations to regulated firms, Journal of Political Economy 94, 614-641.

Miller, N., and Pazgal, A. (2002) Relative performance as a strategic commitment mechanism, Managerial and Decision Economics 23, 51-68.

Novshek, W. (1985) On the existence of Cournot equilibrium, Review of Economic Studies $52,86-98$.

Ritz, R. (2008) Strategic incentives for market share, International Journal of Industrial Organization 26, 586-597.

Sklivas, S.D. (1987) The strategic choice of management incentives, Rand Journal of Economics 18, 452-498.

Stewart, G. (1992) Management objectives and strategic interactions among capitalist and labor-managed firms, Journal of Economic Behavior and Organization 17, 423-431.

Szidarovzsky, F. and K. Yakowitz (1977) A new proof of the existence and uniqueness of the Cournot equilibrium, International Economic Review 18, 787-789. 
Vickers, J. (1985) Delegation and the theory of the firm, Economic Journal 95, 138-147.

Vives, X. (1999) Oligopoly Pricing: Old Ideas and New Tools, The MIT Press, Cambridge.

White, M. (1996) Mixed oligopoly, privatization and subsidization, Economics Letters 53, 189-195. 